\title{
POR UMA ESTÉTICA ANTROPOLÓGICA DESDE A ÉTICA DA ALTERIDADE: Do "estado de exceção" da violência sem memória ao "estado de exceção" da excepcionalidade do concreto*
}

Ricardo Timm de Souza**

SÍNTESE - O texto investiga a dimensão "labiríntica" sociedade contemporânea do ponto de vista de sua autocompreensão conceitual, e a dimensão do "esquecimento" do real concreto, que caracteriza esta sociedade do ponto de vista de suas relações humano-ecológicas; a "emergência" do eticamente "excepcional" no real "estado de exceção em que vivemos", em um cruzamento de categorias levinasianas e benjaminianas, é apresentada como uma possibilidade de escapar a algumas das dificuldades categoriais da filosofia política contemporânea.

PALAVRAS-CHAVE - Alteridade. "Estado de exceção”. Labirinto conceitual. Esquecimento.
ABSTRACT - The text discusses the contemporary society as a society marked by a "labyrinth of abstract concepts", of its self-understanding, and by the strong incapacity to remember the real concrete, from the standpoint of its human, ecological relations. The emergency of the ethically "exceptional" in the actual "state of exception where we live", in the intersection of Levinasian and Bejaminian categories, is presented as a possibility to escape some categorical difficulties of contemporary political philosophy

KEY WORDS - Alterity. "State of exception". Conceptual labyrinth. Forgiveness.

* Este texto sintetiza idéias dispersas em boa parte de nossa produção filosófica, especialmente nos livros Totalidade \& Desagregação - sobre as fronteiras do pensamento e suas alternativas, O tempo e a Máquina do Tempo - estudos de filosofia e pós-modernidade, Sujeito, ética e história - Levinas, o traumatismo infinito e a crítica da filosofia ocidental, Existência em Decisão - uma introdução ao pensamento de Franz Rosenzweig, Sentido e Alteridade - Dez ensaios sobre o pensamento de E. Levinas, Metamorfose e Extinção - sobre Kafka e a patologia do tempo, Ainda além do medo filosofia e antropologia do preconceito, Sobre a construção do sentido - o pensar e o agir entre a vida e a filosofia, Responsabilidade Social - uma introdução à Ética Política para o Brasil do século XXI, Razões plurais - itinerários da racionalidade ética no século XX: Adorno, Bergson, Derrida, Levinas, Rosenzweig, Fontes do humanismo latino - a condição humana no pensamento filosófico moderno e contemporâneo, Ética como fundamento - uma introducão à ética contemporânea, Em torno à Diferença - aventuras da alteridade na complexidade da cultura contemporânea e nos artigos "Justiça, liberdade e alteridade ética", "Três teses sobra a violência", "Humanismo e alteridade. A filosofia frente à radicalidade do desafio humano" e "A dignidade da pessoa humana; uma visão contemporânea". Para referências bibliográficas completas, ver "Referências" ao fim do texto. Uma versão deste texto, intitulada Humano, hoje - Sobre a questão da dignidade humana no discurso filosófico contemporâneo, foi apresentada como Aula magna no Instituto de Filosofia Berthier, Passo Fundo, RS

** PUCRS, Porto Alegre.

\begin{tabular}{l|l|l|l|l|l} 
VERITAS & Porto Alegre & v. 51 & n. 2 & Junho 2006 & p. 129-139
\end{tabular}




\section{Status quaestionis: o labirinto}

"Ai de mim", exclamou o camundongo, "o mundo está ficando cada vez menor. De início era tão grande, que eu me apavorava. Vivia correndo para cá e para lá, e só me tranqüilizava quando via, por fim, paredes bem distantes à esquerda e à direita. Mas o espaço entre essas paredes estreitou-se tão rapidamente que já me encontro na última câmara, e vejo ali no canto a ratoeira onde de certo esbarrarei." "Ora, basta-lhe escolher outro caminho", disse o gato, antes de engoli-lo. Franz KAFKA, Uma fabulazinha ${ }^{1}$

Umas das maiores dificuldades atualmente vivenciadas por quantos escrevem em filosofia com pretensão de legitimidade e conseqüência - ou seja, segundo motivações que estão para além do lúdico e do hipócrita -, é o desafio que se propõe pela superabundância de lugares-comuns na terminologia normalmente utilizada nos textos. Novíssimos alguns, resgatados da poeira do passado outros, os lugares comuns prestam-se a tudo e a nada; dão a ilusão de se estar a tocar ou, ao menos, aproximar, da medula do real, do que verdadeiramente dá e deve dar o que pensar, porém, ao mesmo tempo, multiplicam infinitamente a distância do concreto, ao se formalizarem em palavras grandiosas nas quais tudo cabe, mas que, muitas vezes, nada contêm.

Um exemplo eloqüente do acima referido pode ser observado com os termos, ou o termo composto, "dignidade humana" e seus derivados. Muitos intelectuais contemporâneos honestos e de grande envergadura encontram este tema entre suas questões essenciais, como, aliás, não poderia deixar de acontecer, exatamente por sua honestidade e grandeza intelectual - pois não escapa a ninguém que a questão humana transcende qualquer outro problema filosófico e se entranha nas mais árduas e espinhosas questões de ordem ético-ecológica: questões eminentemente, mas não apenas humanas - em todos os níveis e sentidos de existência de nossa difícil contemporaneidade. Todavia, tal não significa absolutamente que muitos desses pensadores tenham percebido a seara real em que se embrenham. A tradição filosófica possui uma indelével tendência formalizante-universalizante que, embora em crise, parece sobreviver ainda, ainda que a muito custo, em certos ambientes intelectuais de grande influência. ${ }^{2}$ A questão é, em sua essência, simples, e não se trata senão da grande questão, por assim dizer fundante e que estabeleceu os padrões hegemônicos do modus operandi filosófico do pensamento grego em sua linhagem mais clássica: a relação entre o particular e o universal. Esta é a dialética original que se encontra em todos os grandes problemas filosóficos em sua mais viva tradição; a história da filosofia, grosso modo, consiste exatamente na sucessão de respostas que se tem tentado fornecer a esta questão filosófica original.

In: KAFKA, Franz. Contos, Fábulas e Aforismos, Rio de Janeiro: Civilização Brasileira, 1993, p. 29, tradução de Enio Silveira.

Para um breve escorço da história do processo conceitual-totalizante da filosofia, cf. nosso ensaio "Da neutralização da diferença à dignidade da Alteridade - estações de uma história multicentenária" in: SOUZA, R. T. Sentido e Alteridade - dez ensaios sobre o pensamento de Emmanuel Levinas, p. 189-208. 
A nossa questão, por outro lado, diz respeito não a esta questão maior e original, delineada nas origens do logos classificador, mas àquilo a que nos têm levado as respostas dadas a ela. ${ }^{3}$ Um certo excesso de pudor argumentativo, não sem alguma dose de receio em termos de possibilidade de iconoclastia filosófica ou de atentado à tradição, faz normalmente com que muitas obras culminem exatamente no ponto em que deveriam ter iniciado: antes de um profundo reexame das possibilidades de sentido de um termo como "humano", hoje. ${ }^{4}$ Nesta detenção, neste momento incômodo de suspensão de juízo, grandes pensadores têm caído exatamente na contradição extrema - não uma contradição produtiva, iluminadora dos temas tratados, mas em uma contradição mortal, em um beco sem saída, qual o camundongo da conhecida fábula kafkiana. Antes, ansiavam pelas paredes formais da terminologia filosófica consagrada; mas agora, com o derribar dessas paredes, com o estreitar-se paulatino e inelutável na confiança que seríamos capazes de depositar no julgamento excessivamente benevolente de um passado que se mostrou absolutamente cruel para com o particular, para com o outro do(s) conceito(s), dirigem-se para a ratoeira do sem-saída, do "outro" da filosofia enquanto questão humana eminente - ou seja, em última análise, o óbvio conceitual vazio -, prestes a serem devorados pelo gato empírico, a serem soterrados pela coleção catastrófica - para usar uma expressão benjaminiana ${ }^{5}$ - de destroços que se acumulam atrás deles e, em um frêmito de energia ${ }^{6}$ totalizante e por sua própria exuberância, os devorarão na voragem da temporalidade que lhes segue, como aos conceitos, ao encalço, e com a qual, a rigor, não sabem lidar, pois a mais necessária das pedagogias - a do tempo não pertence à cartilha da tradição filosófica na qual foram formados. ${ }^{7}$ Pensamentos que se entendem a si mesmos, já nos dizia Adorno, se nos é possível citá-lo "ao inverso" e sem polemizar, no momento, com sistemas e anti-sistemas filosóficos constituem o não-verdadeiro; e poderíamos acrescentar: pensamentos que celere-

3 Cf. nosso ensaio "O século XX e a desagregação da Totalidade" in: SOUZA, Ricardo Timm de. Totalidade \& Desagregação - sobre as fronteiras do pensamento e suas alternativas., p.15-29.

Cf. a respeito nossa Introdução a SOUZA, R. T. de. Fontes do humanismo latino - A condição humana no pensamento filosófico moderno e contemporâneo, p. 11-20.

5 Lembremos a muito famosa 9. "Tese" de Über den Begriff der Geschichte: “...Há um quadro de Klee que se chama Angelus Novus. Representa um anjo que parece querer afastar-se de algo que ele encara fixamente. Seus olhos estão escancarados, sua boca dilatada, suas asas abertas. O anjo da história deve ter esse aspecto. Seu rosto está dirigido para o passado. Onde nós vemos uma cadeia de acontecimentos, ele vê uma catástrofe única, que acumula incansavelmente ruína sobre ruína e as dispersa a nossos pés. Ele gostaria de deter-se para acordar os mortos e juntar os fragmentos. Mas uma tempestade sopra do paraíso e prende-se em suas asas com tanta força que ele não pode mais fechá-las. Essa tempestade o impele irresistivelmente para o futuro, ao qual ele vira as costas, enquanto o amontoado de ruínas cresce até o céu. Essa tempestade é o que chamamos progresso" (BENJAMIN, W. "Sobre o conceito de história", in: BENJAMIN, Walter. Obras escolhidas - magia e técnica, arte e política, p. 226, trad. de S. P. Rouanet).

6 Cf. nosso "O fim da história, a totalidade rediviva e a metafísica do consumo infinito" in: SOUZA, Ricardo Timm de. Totalidade \& Desagregação - Sobre as fronteiras do pensamento e suas alternativas, p. 101-113.

Sobre a questão da temporalidade, cf. nosso livro Ética como fundamento - uma introdução à ética contemporânea, bem como nosso artigo "A dignidade da pessoa humana: uma visão contemporânea". 
mente se dirigem ao conforto dos ninhos conceituais que engendram, constituem, na temporalidade que não perdoa a hipocrisia intelectual e no hic et nunc da concretude espessa daquilo que é irredutível ao mero conceito, uma indecência intolerável no contraste com a verdade irrepresentável que constitui e se constitui, kantianamente falando, exatamente no limite da representação: o sofrimento do outro. Como constata Adorno em sua análise do pensamento filosófico levada a efeito em seu ensaio "Observações sobre o pensamento filosófico", a obra de Kant significa o último baluarte pré-idealista da coisa que se defende de sua representação: "ninguém pode reproduzir em sua própria imaginação a dor alheia. Até aí chega a apercepção transcendental. Com esta determinação, por mera pertinência, já o próprio eu penso torna-se algo passivo, totalmente distinto da reflexão ativa sobre um meu...". 8 É a compreensão cabal deste fato que explica a insistência especialmente aguda de autores como Franz Rosenzweig, que pretendem ler a história da filosofia ocidental como uma continuidade, com incômodas intermitências, "de Jônia a Jena", ou seja, de Tales a Hegel; separar o pensamento do pensado é, para o filósofo de Kassel, como para muitos outros, a única esperança de saúde para uma razão doente, que se traduz na pergunta obsessiva pela "essência". No fundo, é exatamente esta a denúncia de Adorno, que encontra no pensador de Königsberg, mui corretamente, a meta-intuição do respeito ao concreto para além de qualquer esquematismo: "(em Kant) nenhuma objetividade do pensar enquanto ato seria possível de modo algum, se o pensamento não estivesse em si mesmo ligado, segundo sua própria configuração, ao que não é em si o pensar: ali é onde se deve buscar o que se deveria decifrar no pensar". ${ }^{10}$

Vemo-nos, assim, filósofos e intelectuais em geral ${ }^{11}$ interessados nessa que é a mais filosófica das questões filosóficas, enredados em uma complexa teia de problemas. Por um lado, não podemos abdicar da comunicabilidade inter-racional para evitar a palavra moderna “intersubjetiva”, imprópria, segundo nosso parecer ${ }^{12}-$,

ADORNO, T. W. "Observações sobre o pensamento filosófico", in: ADORNO, T. Palavras e Sinais Modelos críticos 2, p. 17.

9 Cf. ROSENZWEIG, Franz. Das neue Denken, in: Zweistromland - Kleinere Schriften zu Glauben und Denken (Gesammelte Schriften III), p. 143; cf. igualmente nosso Existência em Decisão - uma introdução ao pensamento de Franz Rosenzweig e CASPER, Bernhard. Religion der Erfahrung - Einführungen in das Denken Franz Rosenzweigs.

10 ADORNO, T. W. "Observações sobre o pensamento filosófico", in: ADORNO, T. Palavras e Sinais Modelos críticos 2, p. 17.

11 A filosofia deverá crescentemente se abrir a um crescente fluxo crítico interdisciplinar, sob pena, na melhor das hipóteses, de reprodução dos vícios aqui expostos. Não é nenhum acaso, mas sinal agudo da percepção cabal da questão filosófica medular de que aqui tratamos, que intelectuais provindos das mais diversas áreas têm crescentemente denunciado com profundidade e rigor provavelmente inéditos na história exatamente o mesmo problema geral que aqui abordamos. Veja-se, a título ilustrativo exemplar, na área das ciências jurídicas, o magnífico ensaio de Salo de Carvalho "A ferida narcísica do direito penal (primeiras observações sobre as (dis)funções do controle penal na sociedade contemporânea)", in: GAUER, Ruth M. C. (Org.), A qualidade do tempo: para além das aparências históricas, p. 179-211. Sobre o tema da interdisciplinaridade em geral, cf. PAVIANI, Jayme. Interdisciplinaridades - conceito e distinções, Porto Alegre: Pyr Edições, 2005.

12 Aduzimos as razões da redundância do termo "intersubjetividade", em seu uso contemporâneo, em nosso ensaio "Fenomenologia e Metafenomenologia: substituição e sentido - sobre o tema da subs- 
de nossas experiências com o nosso proprium; e, por outro lado, temos que nos ver com as possibilidades de decaimento no lugar-comum de conceitos esvaziados ou excessivamente fragilizados pela corrosão temporal do empírico; o mundo já não suporta sistemas que desabam, expondo a ingenuidade ou a hipocrisia daqueles que, julgando-se a salvo da história como catástrofe, ${ }^{13}$ neles se haviam refugiado. A resposta plena a este desafio tem de passar necessariamente por um amplo inventário das racionalidades contemporâneas, tarefa que aqui não nos cabe, ${ }^{14}$ e cuja explícita ausência estabelece os limites precípuos do presente texto.

Assim, nosso objetivo no presente texto não é analisar em detalhe as errâncias contemporâneas da razão, o que temos feito em vários outros momentos; ${ }^{15}$ interessanos aqui, muito mais, examinar algumas possíveis vias de acesso à questão humana em termos estritamente contemporâneos. ${ }^{16} \mathrm{O}$ viés que aqui será privilegiado entrelaça memória, estética e ética, pretendendo culminar no resgate dos termos da questão para além dos modelos racionalistas mais em voga no que diz respeito à sua abordagem.

\section{Artes e artimanhas da amnistia}

Refere Swift que o Imperador de Lilliput discernia o movimento do ponteiro dos minutos do relógio; Funes discernia continuamente os tranqüilos avanços da decomposição, das cáries, da fadiga. Notava os progressos da morte, da umidade. Era o solitário e lúcido espectador de um mundo multiforme, instantâneo e quase intoleravelmente preciso. Jorge Luis BORGES, Funes el memorioso ${ }^{17}$

"Funes el memorioso", definido por seu autor como uma longa metáfora da insônia, trata das desventuras deste estranho personagem incapaz de esquecer e de não perceber. Incapaz de conceptualizar, de abstrair? Interessa-nos, aqui, o Funes opaco e insone, que é simplesmente incapaz de ser hipócrita: é-lhe vedada a possibilidade de fingir que não vê o que vê, de fingir que não sente o que sente.

É interessante a abordagem que se faz possível em termos de consciência coletiva contemporânea no que diz respeito a esse tema. Pois vivemos, grosso modo,

tituição no pensamento ético de Levinas", in: SOUZA, Ricardo. Timm de. - OLIVEIRA, Nythamar Fernandes de. (Orgs.) Fenomenologia hoje - existência, ser e sentido no alvorecer do século XXI, p. 379-414.

13 Cf. SELIGMANN-SILVA, M. "História como Catástrofe", in: NESTROWSKY, Arthur - SELIGMANNSILVA, Márcio (Orgs.), Catástrofe e Representação; HOBSBAWM, Eric. Era dos extremos - o breve século XX; ROSENZWEIG, Franz. "Vorwort" a Hegel und der Staat.

14 Nosso livro Razões plurais - itinerários da racionalidade ética no século XX: Adorno, Bergson, Derrida, Levinas, Rosenzweig propõe-se, exatamente, como uma possibilidade de um tal inventário.

5 Cf., por exemplo, em termos mais amplos de análise cultural, nossa coletânea de artigos Em torno à Diferença - aventuras da alteridade na complexidade da cultura contemporânea, e, em termos filosoficamente mais estritos e propositivos, nosso livro Razões plurais - itinerários da racionalidade ética no século XX: Adorno, Bergson, Derrida, Levinas, Rosenzweig.

16 Cf. nossa "Introdução" a SOUZA, R. T., Fontes do humanismo latino - A condição humana no pensamento filosófico moderno e contemporâneo.

7 In: BORGES, J. L., Ficciones, p. 130-131. 
na era anti-Funes, na idade do esquecimento e da não-percepção. Ao contrário de Funes, e mesmo do senso comum e estreito, nossas sociedades são capazes de esquecer até o inesquecível; o que ontem era notícia de absoluta relevância é hoje atirado à vala comum da superprodução de dados midiáticos. O que ontem era questão de vida ou morte, hoje torna-se, como que ao natural, tema de pilhérias e leviandades - o limbo que precede o abismo da não-existência. Vivendo em uma sociedade de produção, consumo, obsolescência e descarte, acostumamo-nos a pensar que absolutamente tudo o que nos diz respeito deve seguir o mesmo ciclo; também as indignações com o abjeto e admirações com o grandioso são efêmeras, e acabam no lugar-comum do mediano - talvez uma forma pior de esquecimento do que o próprio esquecimento. Pois o mediano é o medíocre, onde tudo é igualado a tudo; o suspiro de uma musa televisiva tem exatamente o mesmo valor que o suspiro final de uma criança morrendo de fome ou destroçada por uma bomba. Grita-se tanto, que já não se ouve nada, exceto o ruído cacofônico do entorpecimento dos sentidos e da razão. A razão entorpecida, fragmentada em pequenos espasmos de sobrevivência diuturna, instrumentalizada ao extremo, transforma-se em uma grande máquina de aniquilação da memória; promete-se implícita ou explicitamente o prazer, desde que imediato. Incapaz de entrar em uma verdadeira crise, a mônada racional moderna é evidentemente incapaz de sair dela $;^{18} 0$ mundo das vivências consiste na postergação sine die da percepção do radical daquilo que vai, verdadeiramente, às raízes; o universo do lugar-comum social, transformado em um fátuo suceder-se de imagens - eventualmente desligáveis com uma leve pressão no botão do controle remoto - reduplica a racionalidade instrumental que se aninha em certas dimensões da realidade e dali coordena o todo segundo sua vontade. O mundo é o lugar onde os acontecimentos só têm sentido no presente do indicativo que flui, ágil, em uma miríade de cores, antes que seu peso real seja aferido; a memória é continuamente esvaziada, para dar lugar a mais quinquilharias produzidas em série pela agilidade das racionalidades imagéticas que se sucedem sem fim. Repleto de tudo, o presente encontra-se, na verdade, vazio, pois a multiplicação do irrelevante que toma o lugar do notável tomou para si exatamente essa função: pela demiurgia de artistas que, hábeis como os mágicos de outrora, se especializaram em carregar os cérebros de ilusões, onde o que é verdadeiramente decisivo - em todos os sentidos - fica recalcado pelo excesso de resíduos físicos e mentais que sobraram do momento que já desapareceu. É neste sentido que o mundo contemporâneo é o mundo da antimemória.

Porém, como tudo na história humana, também esta anti-memória tem uma história muito particular: não surgiu por geração espontânea, mas paulatinamente, pela incapacidade de sentir intensamente a realidade do particular. Quando tudo é redutível a um conceito qualquer ou a causalidades fáceis, tudo é aplainado sob a égide da irrelevância, está pronto o momento da pequena grande

18 Cf. SOUZA, R. T., Sobre a construção do sentido - o pensar e o agir entre a vida e a filosofia. 
metamorfose, quando causalidade se transforma em mera casualidade. Ainda a mais deslavada mentira, a mais abjeta hipocrisia, o mais agudo sofrimento e injustiça acabam na vala comum das casualidades, dos acasos mutuamente intercambiáveis porque pretensamente irrelevantes em sua incapacidade de paralisar a roda do mundo. Quando se desloca a lógica do pensar - onde tudo é permitido - para a lógica do agir - onde nem tudo é humanamente e ecologicamente suportável nem deveria ser permitido - então temos à nossa frente uma paisagem inóspita, incapaz de perceber até mesmo o que se perdeu nesse processo. Em outros termos: se o concreto é banal e tudo cabe dentro de um mero conceito instrumental ou operacional, é porque se banalizou a vida. Sim, nossas sociedades são capazes de esquecer até o inesquecível, porque perdoam o imperdoável e justificam teoricamente - muitas vezes com os mais argutos ardis da venerável tradição da amnistia -, o injustificável. Aprendeu-se, com a lógica dos conceitos que só tem realidade na cabeça de quem a pensa, a justificar os desencontros da realidade do concreto que existem para além de uma cabeça que os pense; a vida em geral, a vida humana em particular, transforma-se e reduzse de uma questão vital em uma questão lógica e metodológica. E, por mais que sejam muitos os que, desconfiados, mantenham uma tenaz crivo crítico em relação ao que se passa, muitos são também os sofistas no mau sentido do termo - profetas ao inverso - sempre prontos a chafurdar nos esquemas mentais de intelectos frágeis, para convencê-los de que, com facilidade, as palavras se substituem às coisas. É aí, neste deserto mental cuidadosamente criado e alimentado, que acontece o fundamental para o que o estado de exceção em que vivemos se perpetue: as formalidades são petrificadas. Todo o vital escorre e é devorado por este solo devastado: o tempo, a memória, os tecidos que um dia significaram algo. Uma forma inusitada de violência se instaura. ${ }^{19}$

É esta a razão pela qual qualquer tratamento filosófico do tema da dignidade humana ou dos direitos humanos que não inicie por uma profunda reconstituição histórica do "deserto do real" (Zizek) em que nos encontramos está fadado a um ambíguo destino: para alguns, a angústia de perceberem o descompasso entre o formal e o real, sem saberem por onde começar a limpar o terreno, aprofundando-se muitas vezes na formalidade exatamente por sua ânsia de chegar à realidade; para outros, geralmente os vencedores das grandes guerras e batalhas nas quais a existência sócio-ecológica contemporânea se constitui, a festa sobre os destroços daquilo que se tornou quase nada. ${ }^{20}$ Aos segundos, deixamos os louros de suas vitórias; aos primeiros, nos dirigimos, na intenção de tentar facilitar uma maior compreensão dos termos corretos do que aqui nos interessa.

Cf. SOUZA, R. T., "Três teses sobra a violência".

Cf. SOUZA, R. T., O tempo e a Máquina do Tempo. 


\section{Por uma estética antropológica: \\ do estado de exceção da violência sem memória \\ ao estado de exceção da excepcionalidade do concreto}

A identidade estética deve defender o não-idêntico que a compulsão à identidade oprime na realidade.

T. $A D O R N O^{21}$

A totalidade estética é a antítese da totalidade não-verdadeira

T. ADORNO ${ }^{22}$

Dado o exposto, a nossa posição é clara; a tarefa humana de autocompreensão do sentido contemporâneo do humano corresponde à compreensão das possibilidades da ruptura da Totalidade da violência, na esteira de pensadores como Levinas, Rosenzweig, Derrida e Adorno. Comum a todas estas percepções é a clara circunscrição de um momento, de um instante decisivo, onde a ruptura da Totalidade não-verdadeira, a muito custo sustentada em seu lugar por demiurgias conceituais, não mais se sustenta. Trata-se da irrupção do excepcional, da exceção que trinca as regras da normatividade violenta. Este é o momento da verdadeira possibilidade de instauração do estado de exceção que temos de, humanamente, desejar, se quisermos ser ou permanecer humanos: o estado de exceção verdadeiro no sentido em que Benjamin o propugna. Lembremos a 8. "Tese":

A tradição dos oprimidos nos ensina que o 'estado de exceção' em que vivemos é na verdade a regra geral. Precisamos construir um conceito de verdade que corresponda a essa verdade. Nesse momento, perceberemos que nossa tarefa é originar um verdadeiro estado de exceção... O assombro com o fato de que episódios que vivemos no século XX 'ainda' sejam possíveis não é um assombro filosófico. Ele não gera nenhum conhecimento, a não ser o conhecimento de que a concepção de história da qual emana semelhante assombro é insustentável. ${ }^{23}$

Por onde inicia, portanto, a compreensão daqueles dados básicos que vão fornecer à reflexão o início de uma compreensão mais sólida, em meio à miríade de conceitos grandiosos? Segundo o que aqui propomos, exatamente pela conjunção desses três elementos, dispersos, mas reconhecíveis em meio aos estilhaços do presente: a memória do real, revivido pelo instante presente onde o concreto assume a sua verdadeira forma; a ética, conseqüência da reconsideração radical do sentido do humano enquanto agir e se constituir subjetivamente pelo encontro com a Alteridade; e a estética, antídoto sereno da violência totalitária. É possível então que neste momento decisivo - um momento de nascimento, onde o futuro, desvelado das sombras tautológicas de um presente mortiço, caricatura de suas promessas -, ofereça a nós e às novas gerações o reencontro com o vital propriamente dito, e os conceitos, desinflados e depostos de seus píncaros racionais, não mais cúmplices do maciço da mediocridade, sirvam à sua verdadeira vocação:

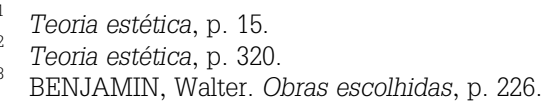


auxiliar o pensamento filosófico, e não se substituir a ele. Teremos então, no dizer de Benjamin, o dia do "juízo final" da realidade, que significa, para nós, o juízo inicial em que a história, julgada, devolve a palavra aos mortos, aos pequenos e fracos, ao Outro, e o impossível acontece: o tempo excepcional não se exaure, mas reconstitui as possibilidades reais de fundamentação do humano e de todas as suas categorias derivadas - quando a palavra "humanismo" não será mais alvo de chacotas, mas a porta para tesouros secretos da vida.

\section{Referências}

ADORNO, Theodor W., Minima moralia, São Paulo, Ática, 1993.

\footnotetext{
- . Palavras e Sinais - Modelos críticos 2, Petrópolis, Vozes, 1995. . Notas de Literatura I, São Paulo: Duas Cidades; Ed. 34, 2003.

—. Ästhetische Theorie, Frankfurt a.m., Suhrkamp (Teoria estética, São Paulo, Martins Fontes).

- Palavras e Sinais - Modelos críticos 2, Petrópolis, Vozes, 1995.

. Negative Dialektik, Frankfurt a. M., Suhrkamp.
}

ADORNO, T.; HORKHEIMER, Max. Dialética do Esclarecimento, Rio de Janeiro, Jorge Zahar, 1985.

AGAMBEN, Giorgio. Homo sacer - o poder soberano e a vida nua I, Belo Horizonte, Ed. da UFMG, 2002 .

. Estado de Exceção, São Paulo: Boitempo, 2004.

ALTER, Robert. Anjos necessários - tradição e modernidade em Kafka, Benjamin e Scholem, Rio de Janeiro, Imago, 1992.

BAUMAN, Zygmunt. Em busca da política, Rio de Janeiro: Jorge Zahar Editores, 2000.

BENJAMIN, Walter. Obras escolhidas - magia e técnica, arte e política, São Paulo: Brasiliense.

. Obras escolhidas II - Rua de mão única, São Paulo: Brasiliense.

Brasiliense.

Obras escolhidas III - Charles Baudelaire, um lírico no auge do capitalismo, São Paulo:

. A modernidade e os Modernos, Rio de Janeiro, Biblioteca Tempo Universitário, 1975.

. Das Passagen-Werk, Frankfurt a. M., Suhrkamp, 1983 (2 vols.).

BORGES, Jorge Luis. Ficciones, Madrid: Alianza Editorial, 1995.

DERRIDA, Jacques. Adeus a Emmanuel Levinas, São Paulo, Perspectiva, 2003.

— Espectros de Marx, Rio de Janeiro, Relume Dumará, 1994.

—. Gesetzkraft -, Der "mystische Grund der Autorität, Frankfurt a.M., Suhrkamp, 1991.

—. "Force de Loi: le "fondement mystique de l'autorité", in: Deconstruction and the possibility of justice, Cardozo Law Review, v. 11, july/aug. 1990, n. 5-6.

DREIZIK, Pablo. (Org.) La memoria de las cenizas, Buenos Aires: Patrimonio Argentino, 2001.

HAVERKAMP, Anselm (Org.). Gewalt und Gerechtigkeit - Derrida-Benjamin, Frankfurt a. M., Suhrkamp, 1994. 
HOBSBAWM, Eric. Era dos extremos - o breve século XX, São Paulo, Cia. das Letras, 1997.

KAFKA, Franz. Contos, Fábulas e Aforismos, Rio de Janeiro: Civilização Brasileira, 1993.

LEVINAS, Emmanuel. Entre nós - Ensaios sobre a Alteridade, Petrópolis, Vozes, 1997.

Humanismo do outro homem, Petrópolis, Vozes, 1996.

. Ética e Infinito, Lisboa, Edições 70.

. Totalité et Infini, Den Haag, Martinus Nijhoff, 1971.

. Da existência ao existente, Campinas, Papirus, 1998.

2001.

Do sagrado ao santo - cinco novas leituras talmúdicas, Rio de Janeiro, Civilização Brasileira,

— De outro modo que ser o más allá de la esencia, Salamanca, Sígueme, 1986.

- De Deus que vem à idéia, Petrópolis, Vozes, 2002.

. Autrement qu'être ou au-delà de l'essence, Den Haag, 1974.

LÖWY, Michel. Redenção e Utopia, São Paulo, Companhia das Letras, 1989.

. Romantismo e Messianismo, São Paulo, Perspectiva-EDUSP, 1990.

MATE, Reyes. Memórias de Auschwitz - atualidade e política, São Leopoldo: Nova Harmonia, 2005.

. La razón de los vencidos, Barcelona, Anthropos, 1991.

MAYER, Hans. In den Ruinen des Jahrhunderts, Frankfurt am Main, Suhrkamp, 1997.

NESTROWSKY, Arthur; SELIGMANN-SILVA, Márcio (Orgs.), Catástrofe e Representação, São Paulo, Escuta, 2000.

ROSENZWEIG, Franz. Das Büchlein des gesunden und kranken Menschenverstandes, Frankfurt a. M., Jüdischer Verlag, 1992.

Hegel und der Staat, Aalen: Scientia Verlag, 1982.

. Zweistromland - Kleinere Schriften zu Glauben und Denken (Gesammelte Schriften III), Dordrecht/Boston/Lancaster, Martinus Nijhoff Publishers, 1984, onde se encontram o texto "Das neue Denken".

. Der Stern der Erlösung, Frankfurt a. M., Suhrkamp, 1996.

SOUZA, Ricardo Timm de. Totalidade \& Desagregação - sobre as fronteiras do pensamento e suas alternativas, Porto Alegre: EDIPUCRS, 1996.

O tempo e a Máquina do Tempo - estudos de filosofia e pós-modernidade, Porto Alegre: EDIPUCRS, 1998.

Sujeito, ética e história - Levinas, o traumatismo infinito e a crítica da filosofia ocidental, Porto Alegre: EDIPUCRS, 1999.

. Existência em Decisão - uma introdução ao pensamento de Franz Rosenzweig, São Paulo: Perspectiva, 1999.

Sentido e Alteridade - Dez ensaios sobre o pensamento de E. Levinas, Porto Alegre: EDIPUCRS, 2000.

. Metamorfose e Extinção - sobre Kafka e a patologia do tempo, Caxias do Sul: EDUCS, 2000. 
Ainda além do medo - filosofia e antropologia do preconceito, Porto Alegre: DaCasaPalmarinca, 2002

. Sobre a construção do sentido - o pensar e o agir entre a vida e a filosofia, São Paulo: Perspectiva, 2003

Razões plurais - itinerários da racionalidade ética no século XX: Adorno, Bergson, Derrida, Levinas, Rosenzweig, Porto Alegre: EDIPUCRS, 2004.

Fontes do humanismo latino - A condição humana no pensamento filosófico moderno e contemporâneo, Porto Alegre: EDIPUCRS, 2004.

Ética como fundamento - uma introdução à ética contemporânea, São Leopoldo: Nova Harmonia, 2004

Em torno à Diferença - aventuras da alteridade na complexidade da cultura contemporânea, Rio de Janeiro: Lumen Juris, 2006

"Justiça, liberdade e alteridade ética. Sobre a questão da radicalidade da justiça desde o pensamento de E. Levinas", in: Veritas - Revista de Filosofia, v. 46 n. 2, junho 2001, p. 265-274.

. "Ética e Desconstrução - Justiça e linguagem desde "Force de Loi: le "fondement mystique de l'autorité"”, de J. Derrida", in: Veritas, junho/2002.

. "Três teses sobra a violência", in Civitas - Revista de Ciências Sociais, PUCRS, ano 1, n. 2, dez/2001, p. 7-10.

"Humanismo e alteridade. A filosofia frente à radicalidade do desafio humano", in: PAVIANI, Jayme; DAL RI Jr., Arno (Orgs.), Humanismo latino no Brasil de hoje, Belo Horizonte, Editora da PUC-MG, 2001.

. "A dignidade da pessoa humana; uma visão contemporânea", in: Filosofazer, Passo Fundo, ano XIV, n. 26, p. 7-36, 2005-II.

SOUZA, Ricardo Timm de. (Org.). Ciência e Ética - os grandes desafios, Porto Alegre: EDIPUCRS, 2006.

; OLIVEIRA, Nythamar Fernandes de. (Orgs.) Fenomenologia hoje - existência, ser e sentido no alvorecer do século XXI, Porto Alegre, EDIPUCRS, 2001.

Fenomenologia hoje II - significado e linguagem, Porto Alegre, EDIPUCRS, 2002.

SUSIN, Luiz Carlos. O Homem messiânico - uma introdução ao pensamento de Emmanuel Levinas, Porto Alegre, EST/Vozes, 1984.

; et al. (Orgs.). Éticas em Diálogo - Levinas e o pensamento contemporâneo: questões e interfaces, Porto Alegre, EDIPUCRS, 2003.

TIBURI, Márcia. Filosofia Cinza, Porto Alegre: Escritos, 2004

. Uma outra história da razão, São Leopoldo: UNISINOS, 2003.

TIBURI, M.; KEIL, I. (Orgs.). O Corpo Torturado, Porto Alegre: Escritos, 2004.

ZIZEK, Slavoj. Bem-vindo ao deserto do real!, São Paulo: Boitempo, 2003 